\title{
Molecular Forms and Subunit Structure of the Acetylcholine Receptor in the Central Nervous System of Insects ${ }^{1}$
}

\author{
H. BREER, ${ }^{2}$ R. KLEENE, AND G. HINZ \\ University of Osnabruck, Department Zoophysiology, Postfach 4469, 4500 Osnabrück, West Germany
}

\begin{abstract}
The nicotinic acetylcholine receptor as probed by $\alpha$-bungarotoxin binding has been isolated from detergent-solubilized ganglionic membrane preparations from the insect, Locusta migratoria. The isolation and characterization of the receptor protein was achieved by preparation of membrane fragments, extraction by sodium deoxycholate, centrifugation on sucrose density gradient, affinity chromatography, gel electrophoresis, and immunoblotting. The purified receptor protein migrated as a single band on polyacrylamide when native $\left(M_{\mathrm{r}}=250,000\right.$ to 300,000$)$ but also under denaturing conditions $\left(M_{\mathrm{r}}=65,000\right)$ and cross-reacted with some monoclonal antibodies against the Torpedo receptor. In immunohistochemical approaches using polyclonal antibodies the acetylcholine receptor antigenic sites could topochemically be identified at very distinct zones in the neuropil of locust ganglia. The results suggest that the acetylcholine receptor in the central nervous system of insects represents an oligomeric complex composed of four identical or very similar subunits and thus may represent a prototype of the recently proposed homo-oligomeric ancestral acetylcholine receptor.
\end{abstract}

The receptors for acetylcholine at the peripheral synaptic sites, i.e, in fish electromotor synapses and vertebrate neuromuscular junctions, are well characterized proteins, composed of four subunits present in the ratio of 2:1:1:1 (Conti-Tronconi and Raftery, 1982; Maelicke, 1984; Popot and Changeux, 1984). Since acetylcholine is present to a greater or lesser extent also in the central nervous tissue, there is a great deal of interest in the molecular identity of the receptor in the central nervous system (CNS).

The identification of peripheral acetylcholine receptors was greatly facilitated by the use of snake venom $\alpha$-toxins, notably $\alpha$-bungarotoxin ( $\alpha$-BGTX). Although electrophysiological evidence for the existence of nicotinic acetylcholine receptors in the CNS has been presented (Oswald and Freeman, 1981) and binding sites for $\alpha$ toxins have also been found in brain tissue, it is presently highly controversial whether these $\alpha$-BGTX-binding sites in central nervous tissue represent really functional receptors (Morley and Kemp, 1981).

Studies on the neuroanatomical distribution of the main components of the cholinergic system have demonstrated that only a

Received February 27, 1985; Revised April 18, 1985;

Accepted April 18, 1985

\footnotetext{
${ }^{1}$ We would like to thank Prof. A. Maelicke for providing the monoclonal antibodies and Mrs. U. Mädler for preparing the immunohistochemical samples. This work was supported by the Deutsche Forschungsgemeinschaft (SFB 171-84).

${ }^{2}$ To whom correspondence should be addressed.
}

fraction of the total neurons in the brain and spinal cord of vertebrates are cholinergic in nature (McGeer et al., 1978) and, furthermore, that muscarinic receptors predominate in this tissue (Salvaterra and Foders, 1979; Breer, 1981a). Thus, the brain tissue of vertebrates seems not to be the favorite tissue to study the molecular properties of acetylcholine receptor in nerve cells. The CNS of insects may be much more appropriate, since acetylcholine has been shown to be the major excitatory transmitter in insect ganglia (Florey, 1963) and several recent studies have demonstrated the presence of saturable, specific binding sites for $\alpha$-BGTX with distinct nicotinic pharmacology in the CNS of various insect species, and the concentration of these "receptors" was shown to be considerably higher in insect ganglia than in any region of mammalian brain (Dudai, 1979; Breer, 1981b); furthermore, for the nervous tissue of insects there is definite electrophysiological evidence that $\alpha$-BGTX blocks the function of postsynaptic acetylcholine receptors, suggesting that in this tissue the toxin-binding sites represent acetylcholine receptors (Sattelle et al., 1980).

Thus, the nervous tissue of insects may offer a promising starting material for characterizing the nicotinic acetylcholine receptor at cholinergic synapses of nerve cells and to compare its molecular properties with the well characterized receptor of muscle cells and electrocytes. Furthermore, the identification of the receptor protein from insect CNS will yield some valuable information for the efforts to characterize the nicotinic binding sites in the CNS of vertebrate species. Thus, studies on the insect receptor may contribute to the unraveling of the phylogenetic development of the acetylcholine receptor which is currently under intensive discussion due to the very pronounced sequence homology between the subunits of the receptor molecule in electrocytes (Raftery et al., 1980).

Here we report the isolation of the acetylcholine receptor from the nervous system of the locust, the characterization of its molecular forms, as well as the definition of its subunit structure and its location in the insect nervous system.

\section{Materials and Methods}

Adult Locusta migratoria migratoroides (males and females) were received from the Insektarium Dr. Frieshammer, Jaderberg. The insects were kept in special cages several days before usc. All of the chemicals werc of reagent grade and solutions were prepared in glass-distilled water. Cyanogen bromide-activated Sepharose 4B and $\alpha$-toxins from Bungarus multicinctus as well as $d$-tubocurarine and carbamylcholine were obtained from Sigrna Chemical Co. ${ }^{125}$-labeled $\alpha$-BGTX was received from Amersham

Isolation of neuronal membrane fraction. Locusts were anesthetized by cooling at $4^{\circ} \mathrm{C}$ and decapitated. The head and thoracic ganglia were dissected and collected at $0^{\circ} \mathrm{C}$ or stored at $-70^{\circ} \mathrm{C}$. The nervous tissue of 15 to 20 insects were homogenized in a prechilled microhomogenizer using an antiprotease buffer $(10 \mathrm{~mm}$ sodium phosphate, $\mathrm{pH} 7.4,100 \mathrm{mM} \mathrm{NaCl}, 5$ mM EDTA, $3 \mathrm{~mm}$ EGTA, $0.1 \mathrm{~mm}$ phenylmethylsulfonyl fluoride (PMSF), $0.2 \%$ sodium azide). Nuclei and debris were separated by centrifugation at 1,000 $\times g$ for $10 \mathrm{~min}$. The supernatant was centrifuged at $45,000 \times g$ for $30 \mathrm{~min}$ 
at $4^{\circ} \mathrm{C}$. The resulting pellet was considered as neuronal membrane preparation. Sodium deoxycholate ( $1 \%$ final concentration) was added to the membrane fraction resuspended in antiprotease buffer; the mixture was incubated for $30 \mathrm{~min}$ at $4^{\circ} \mathrm{C}$. Unsolubilized material was removed by centrifugation at $20,000 \mathrm{~g}$ for $30 \mathrm{~min}$.

Binding assays. Aliquots of the resuspended membranes were incubated with $\left[{ }^{125} \mathrm{l}\right]-\alpha$-BGTX $(0.5 \mathrm{nM}, 0.3 \mu \mathrm{Ci})$, and the specific binding was determined by the filtration technique using Whatman GF/C filters as described previously (Breer, 1981b). Incubation was performed for $2 \mathrm{hr}$ at $20^{\circ} \mathrm{C}$ or at $4^{\circ} \mathrm{C}$ overnight To minimize the unspecific binding to the filters, the discs were preincubated in bovine serum for at least $1 \mathrm{hr}$ prior to use.

Toxin binding of the detergent-solubilized membrane proteins was determined using a modified version of the DEAE disc procedure of Schmidt and Raftery (1973).

Sucrose density gradient centrifugation. Linear gradients from 5 to $20 \%$ sucrose ( $w / v)$ were prepared in $10 \mathrm{~mm}$ Tris- $\mathrm{HCl}$, pH 7.4; $100 \mathrm{~mm} \mathrm{NaCl}, 5 \mathrm{~mm}$ EDTA, $3 \mathrm{mM}$ EGTA, $0.1 \mathrm{mM}$ PMSF, $0.02 \%$ sodium azide, and different concentrations of various detergents by means of a gradient former; the linearity of the density was checked by refractometry. Detergent solution $(200 \mu l)$ containing deoxycholate-solubilized receptors was layered on top of a preformed gradient and centrifuged for $13 \mathrm{hr}$ at $40,000 \mathrm{rpm}$ in a Beckman SW-41 rotor. Catalase and phosphatase were included as internal markers in selected runs. For fractionation of the gradient a capillary was carefully inserted from the top into the gradient almost to the bottom of the tubc, and the solution was continuously suctioned off through the capillary and collected in appropriate fractions. Binding activity in each fraction was deterrinied by incubaling an aliquol wilh $\left[{ }^{125} \mathrm{I}\right]-\alpha$-BGTX for 2 lo $3 \mathrm{hir}$ al $25^{\circ} \mathrm{C}$ followed by filtration on DE-81 discs.

Affinity chromatography. Affinity gel was prepared according to the method of Lindström et al. (1981). Cyanogen bromide-activated Sepharose 4B was swollen in sodium carbonate buffer, $\mathrm{pH} 9.6$, and incubated with $\alpha$ BGTX overnight for coupling. The gel was then treated with glycine $(1 \mathrm{M})$ to mask the unreacted coupling sites, subsequently loaded into a column, and extensively washed. A deoxycholate extract was incubated with the gel overnight; thereafter the column was washed twice with $5 \mathrm{ml}$ of buffer $(10$ mM Tris- $\mathrm{HCl}, \mathrm{pH} 7.4,100 \mathrm{~mm} \mathrm{NaCl}, 5 \mathrm{~mm}$ EDTA, 3 mm EGTA, $0.1 \mathrm{~mm}$ PMSF, $0.02 \%$ sodium azide, $0.1 \%$ sodium deoxycholate) to remove the nonspecific bound proteins. Proteins selectively bound by the affinity gel were subsequently eluted with $1 \mathrm{~mm} d$-tubocurarine followed by $0.1 \mathrm{M}$ carbamylcholine, $5 \mathrm{ml}$ each. The eluates were dialyzed overnight against $1 \mathrm{~mm}$ Tris- $\mathrm{HCl}, \mathrm{pH}$ 7.4, to remove the eluting cholinergic ligands, and the resulting protein solution was concentrated using a Speedvac concentrator lyophilizer.

Micropolyacrylamide electrophoresis. Due to the very limited amount of proteins, the electrophoretic analysis of polypeptide pattern was performed on microscale system with continous as well as gradient polyacrylamide gels. The microscale electrophoresis offers the advantage of increasing sensitivity without any loss of reproducibility of polypeptide resolution (Poehling and Neuhoff, 1980). Thin polyacrylamide separation gels were produced from $12.5 \%$ acrylamide solution according to the method of Laemmli (1970). A linear acrylamide gradient gel $(2.5$ to $15 \%)$ was produced with a gradient mixer and, after polymerization, the stacking gel was formed. Samples, boiled in sample buffer for $3 \mathrm{~min}$, were loaded onto the gel. A Tris (25 mm)/ glycine (192 mM) buffer, $\mathrm{pH} 8.3$, containing $0.1 \%$ sodium dodecyl sulfate (SDS), was used as electrode buffer. Polypeptides were visualized using the ultrasensitive silver-staining procedure (Eschenbruck and Bürk, 1982) or, alternatively, with Coomassie brilliant blue. Gels were scanned with a Desaga densitometer.

Crosslinking experiments. Glutaraldehyde was employed to crosslink [ $\left.{ }^{125}\right]$ $-\alpha$-BGTX $(0.3 \mu \mathrm{Ci})$ to the binding protein. Crude membranes were incubated for $1 \mathrm{hr}$ at $25^{\circ} \mathrm{C}$ with [ [25)]- $\alpha$-BGTX; subsequently, prefiltered glutaraldehyde was added to the suspension at a final concentration of $0.25 \%$, and incubation was continued for $30 \mathrm{~min}$, followed by centrifugation; thereafter the membranes were solubilized with deoxycholate $(1 \%)$. Detergent extracts and partially purified receptor preparations were labeled and crosslinked in the same way, followed by separation of polypeptides on polyacrylamide gradient gels without SDS and reducing agents, but in the presence of deoxycholate. The gels were fixed, stained, and dried, and finally exposed to $x$-ray film (Kodak $X$-omat) for 2 to 5 days at $-80^{\circ} \mathrm{C}$.

Preparation of polyclonal antibodies. Affinity-purified binding protein emulsified in an equal volume of Freund's adjuvant was injected subcutaneously into rabbits at multiple sites. Rabbits were bled every 2 weeks and administered a booster injection every 4 weeks.

Immunoblotting. Following electrophoresis the transfer of polypeptides from polyacrylamide gels to sheets of nitrocellulose (Schleicher \& Schüll, BA 85) was accomplished in a cooled Bio-Rad electroblot apparatus overnight according to the method of Towbin et al. (1979) as modified by Burnette
(1981). After blocking the remaining attachment sites, the blot was reacted with cell culture supernatant of the hybridoma clone N2-A9-E10 (Watters and Maelicke 1983; kindly provided by Prof. A. Maelicke), which was proven to secrete antibodies against the Torpedo receptor. Following the antigenantibody reaction, the blot was washed and treated with rabbit anti-mouse IgG which had been conjugated to peroxidase (Amersham). The reactive bands were visualized by enzyme reaction with $3,3^{\prime}$-diaminobenzidine and $\mathrm{H}_{2} \mathrm{O}_{2}$.

Immunohistochemistry. The mesothoracic ganglia of locust were excised, quickly frozen, and sectioned in a cryostat; the sections were dried and fixed in paraformaldehyde. After preincubation, the specimens were incubated with rabbit anti-(65-kilodalton (kd) protein) antiserum or with preimmune serum at the same dilution for control. Following this incubation the slides were rinsed with phosphate-buffered saline containing $1 \%$ normal goat serum and then incubated with goat anti-rabbit lgG. Subsequently the samples were rinsed and further incubated for 30 min with a solution containing a soluble complex of peroxidase-rabbit antiperoxidase (Sternberger). After this last incubation the samples were rinsed in buffer and the bound peroxidase was then reacted with $0.06 \%$ hydrogen peroxide and $3,3^{\prime}$-diaminobenzidine $(0.6$ $\mathrm{mg} / \mathrm{ml}$ ) (Salvaterra et al., 1985).

\section{Results}

A whole nervous system of an adult locust (head and thoracic ganglia) contains approximately 2 pmol of $\alpha$-BGTX-binding sites. Solubilization of the toxin-binding components from neuronal mem. branes was achieved with anionic detergents, such as sodium deoxycholate, without affecting the features of toxin-receptor interaction. The detergent extract obtained after incubating membrane fractions with sodium deoxycholate $(1 \%)$ in antiprotease buffer for $30 \mathrm{~min}$, followed by centrifugation at $45,000 \times g$ for $30 \mathrm{~min}$, was submittcd to various procedures for determining the molecular size and homogeneity of the putative receptor protein.

A detergent extract, supplemented with markers like blue dextran, catalase, and phosphatase, was subjected to gel permeation on a Sephadex G-150 column. Most of the binding sites were detected in the elution fractions right after the void volumc, prior to catalasc, indicating that the solubilized binding components are macromolecules, larger than catalase. However, the apparent molecular weight may be an overestimation caused by an excess of detergent as was frequently observed for membrane proteins (Biesecker, 1973).

As an alternative test for homogeneity of the $\alpha$-BGTX-binding proteins, a detergent extract was submitted to sedimentation in sucrose density gradients containing Triton X-100 $(1 \%)$. A typical sedimentation protile is presented in Figure 1. It is evident that the receptor sediments as one major protein species, close to catalase;

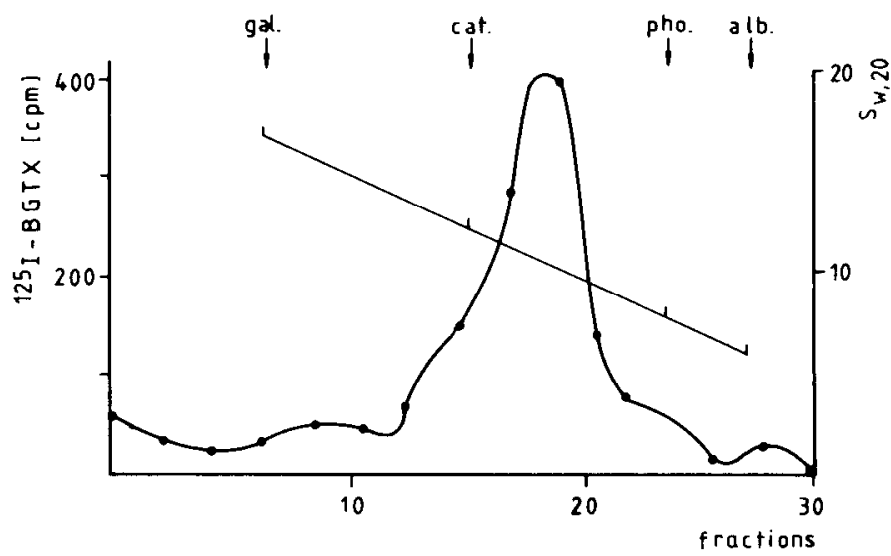

Figure 1. Sedimentation of a detergent-solubilized $\alpha$-BGTX-binding protein in a 5 to $20 \%$ sucrose density gradient in the presence of $1 \%$ Triton $X-100$. After centrifugation $\left(100,000 \times \mathrm{g}, 13 \mathrm{hr}, 4^{\circ} \mathrm{C}\right)$, the fractions of the gradient were analyzed for BGTX binding activity. The arrows indicate the positions of $\beta$-galactosidase ( $\mathrm{gal} .=16 \mathrm{~S}$ ), catalase $(\mathrm{cat} .=11.4 \mathrm{~S})$, phosphorylase $\mathrm{b}$ (pho. $=8 \mathrm{~S}$ ), and albumin (alb. $=6.4 \mathrm{~S}$ ). The position of the binding peak corresponds to $10 \mathrm{~S}$. 
its position corresponds to a sedimentation coefficient of about $10 \mathrm{~S}$. Essentially the same results were obtained if a purified receptor preparation, received by affinity chromatography (see below), was applied on the gradient; these results indicate that purification obviously did not alter the hydrodynamic properties of the receptor macromolecules. The sedimentation coefficient of approximately $10 \mathrm{~S}$ suggests that the apparent molecular weight of the insect acetylcholine receptor is slightly higher than that reported for receptors from electric tissue for which sedimentation coefficients of $9 \mathrm{~S}$ were determined (Conti-Tronconi and Raftery, 1982).

In order to achieve additional information on the hydrodynamic properties of the insect receptor, further analyses were performed using gradients with low concentrations of detergents. In the presence of only $0.1 \%$ Triton X-100, another population of binding proteins was detected centered around $15 \mathrm{~S}$; the number of binding sites in the $10 \mathrm{~S}$ position was proportionally reduced. These changes in the hydrodynamic properties were not due to some special effects of Triton X-100, e.g., oxidizing contaminants (Ashami and Catravas, 1980), but were obviously caused by a critical detergent concentration, as became evident in experiments using different detergents. Thus, at very low detergent concentrations receptor proteins solubilized from neuronal membranes may aggregate by hydrophobic interaction and thus produce multimeric complexes. A similar observation has recently been reported for the acetylcholine receptor from the electric tissue of Torpedo (Rüchel et al., 1981). Since the hydrodynamic behavior of the binding protein is expected to primarily reflect the homogeneity of the receptor-carrying micelles rather than that of the receptors themselves, based on the data presented so far, it cannot be decided whether a unique receptor protein exists in the insect nervous tissue.

As an alternative to the sucrose gradient centrifugation technique polyacrylamide gradient gel electrophoresis was employed to study the properties of the native receptor protein under nondenaturing conditions. In a gradient gel the mobility of the migrating polypeptide will approach zero as soon as the matrix pore size is too small for the molecule; thus, the position in the gel will reflect molecular weight and shape of the protein under study (Rüchel et al., 1981). To identify the binding protein in the polypeptide pattern from a crude preparation, the receptor proteins were labeled with $\left[{ }^{125} \mid\right]-\alpha$-BGTX; labeled toxin was crosslinked onto the protein by glutaraldehyde treatment prior to electrophoresis under nondenaturing conditions. Membrane preparations, solubilized membrane proteins, and partially purified receptor preparations (10 S fractions from a density gradient) from locust ganglionic tissue were labeled and crosslinked with [ $\left.{ }^{125} 1\right]-\alpha$-BGTX and subsequently processed for gradient electrophoresis. After electrophoretic separation followed by autoradiography, only one single major band was found to be labeled (Fig. 2). The position of the labeled band in the gel corresponds to a molecular weight between 250,000 and 300,000 . The receptor protein, purified to homogeneity by affinity chromatography using Sepharose 4B gel coupled with $\alpha$-BGTX (see below) was electrophoresed on an equivalent gradient gel; thereafter only a single staining protein band could be visualized using the sensitive silverstaining procedure (Fig. 3, lane 3 ). The position of this band coincided with the bands labeled by radioactive $\alpha$-BGTX in crude preparations and detected by autoradiography. The concordance of the position of the radioactivity band and of the staining band was evident. It should be noted that the mobility of the free receptor and the receptor-toxin complex should be very much the same in gels due to the very small net charges on the toxin $(\mathrm{pl}=9.8)$ at the high $\mathrm{pH}$ values in the gels. A similar co-migration of receptor and receptor-toxin complex has been reported by Meunier et al. (1974) for the receptor from Electrophorus electricus. The results from gradient electrophoresis experiments demonstrate that the native acetylcholine receptor from insect nervous tissue represents a macromolecule of 250,000 to 300,000 daltons and thus confirm the characteristics of the receptor protein revealed by centrifugation and gel filtration.

In order to elucidate the subunit composition of high molecular weight receptor protein from insects, affinity-purified receptors were used for further analysis. The receptor protein was isolated from detergent extracts of membrane preparations isolated from freshly dissected locust ganglia and purified by affinity chromatography utilizing $\alpha$-BGTX as ligand immobilized on Sepharose 4B. The affinity gel was shown to bind more than $90 \%$ of the solubilized receptor protein applied onto the column. In the extensive washing steps, most of the protein was eluted, but very few binding sites were eluted; and adsorbed receptor molecules were recovered by biospecific elution using carbamylcholine or $d$-tubocurarine. The resulting eluate fractions contained very small amounts of protein but almost all of the toxin-binding sites; thus, an enormous purification was achieved (Breer et al., 1984).

As a first step for dissecting the native receptor, the purified protein isolated in the presence of $N$-ethylmaleimide to protect disulfide bridges, was treated with denaturing detergent (SDS), but under nonreducing conditions, followed by electrophoresis on a linear polyacrylamide gradient gel (2.5 to $20 \%$ ). After silver staining, one distinct band could be identified, which corresponds to $M_{\mathrm{r}}=$ 260,000 , obviously equivalent to the native receptor protein (Fig. 3 ). If the protein solution in SDS sample buffer was boiled prior to applying onto a gradient electrophoresis, in addition, a further migrating band corresponding to $M_{r}=130,000$ was observed. These

1.

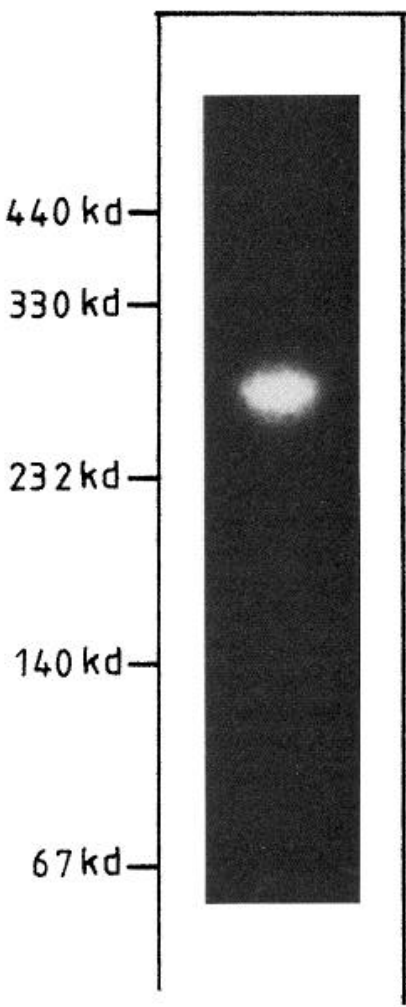

Figure 2. Autoradiogram showing the native receptor labeled with [ $\left.{ }^{1<0}\right]-\alpha$ BGTX and crosslinked by glutaraldehyde followed by electrophoretic separation on polyacrylamide gradient gels under nondenaturing conditions and in the presence of $1 \%$ deoxycholate. In the membrane preparation (lane 1), the detergent extract (lane 2), and the partially purified receptor preparation (lane 3), only one protein band was labeled, which corresponds to $M_{r}=$ 250,000 to 300,000 , as determined by comparing with standard proteins (Pharmacia, HMW calibration kit: ferritin $=440 \mathrm{kd}$, thyroglobulin subunit $=$ $330 \mathrm{kd}$, catalase $=232 \mathrm{kd}$, lactate dehydrogenase $=140 \mathrm{kd}$, albumin $=67$ kd). In lanes 2 and 3 the distribution of radioactivity is not in such a sharp band as in lane 1 . This is probably due to the glutaraldehyde remaining in the sample during electrophoresis, whereas in the membrane preparation (lane 1) the excess of glutaraldehyde was removed prior to solubilization. 
results suggest that under more rigorous denaturing conditions $(1 \%$ SDS, boiling for several minutes) the receptor protein disintegrates into two identical polypeptides.

In subsequent experiments, reducing agents, such as 2-mercaptoethanol or dithiothreitol (DTT), were included in the sample buffer, and the sample was briefly boiled before applying onto a continuous polyacrylamide gel (12.5\%). After DTT treatment, followed by iodoacetamide to prevent re-forming of disulfide bridges, only one protein band could be visualized in the gel after separation and staining either by Coomassie blue or silver stain. The position in the gel corresponds to $M_{\mathrm{r}}=65,000$ (Fig. 4, lane 3); the proteins of this band were selectively separated from the multiple bands seen in the detergent extract (Fig. 4, lane 2). If the sample was extensively boiled in sample buffer (SDS, mercaptoethanol), or if stored for several days prior to electrophoresis, a second component with an apparent $M_{r}=58,000$ was faintly detectable (see also Breer et al., 1984); this is probably due to proteolytic nicking.

In order to demonstrate that the $65-\mathrm{kd}$ band indeed originated from a 130-kd dimer, the samples were treated with different concentrations of DTT prior to electrophoresis. As can be seen in Figure

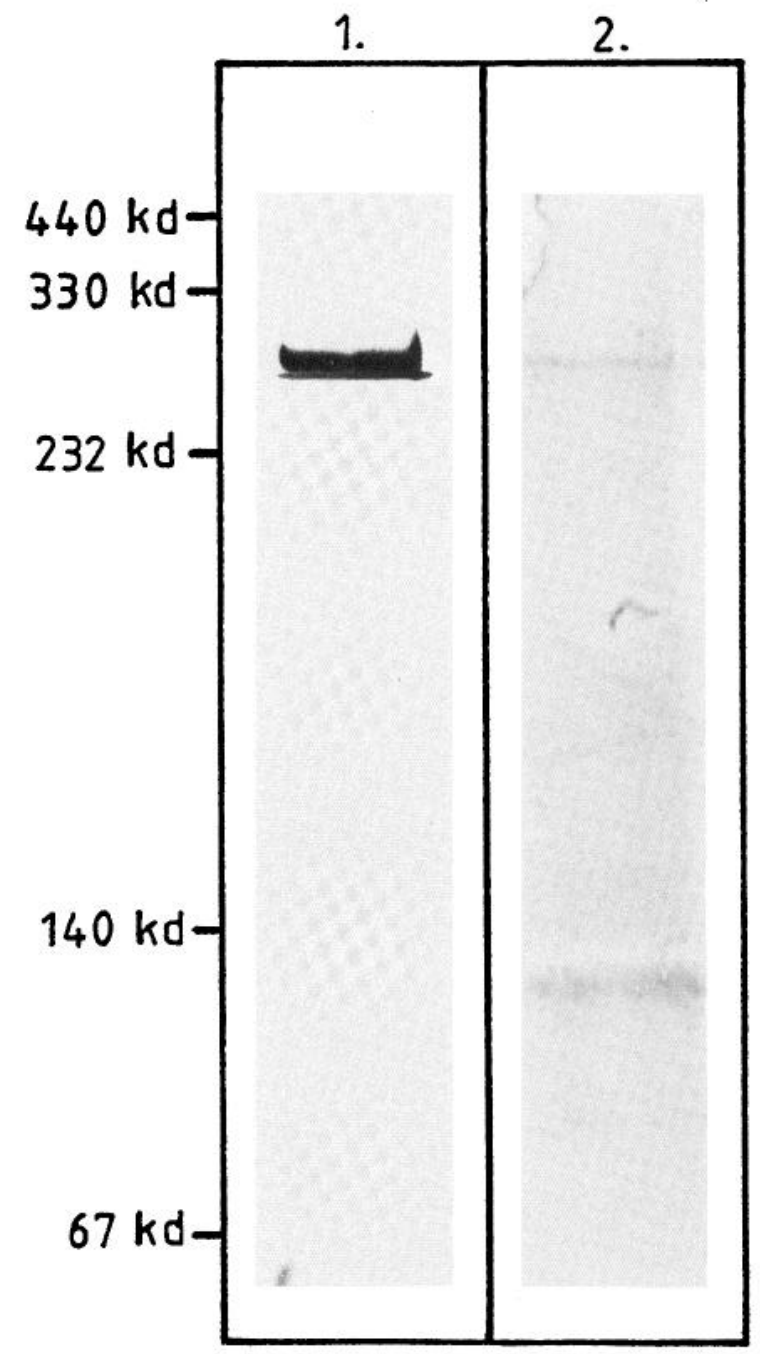

Figure 3. Electrophoretic separation of the affinity-purified binding protein in gradient gels under nonreducing conditions. All steps of the purification were carried out in the presence of $\mathrm{N}$-ethylmaleimide in order to protect disulfide bridges. A single band which corresponds to $M_{t}=250,000$ to 300,000 is visualized by silver staining, if the sample was treated with $1 \%$ deoxycholate only (lane 1). Sample treatment with SDS, however, caused the appearance of a second band with an apparent $M_{t}=130,000$ (lane 2).
1.

2.

3.

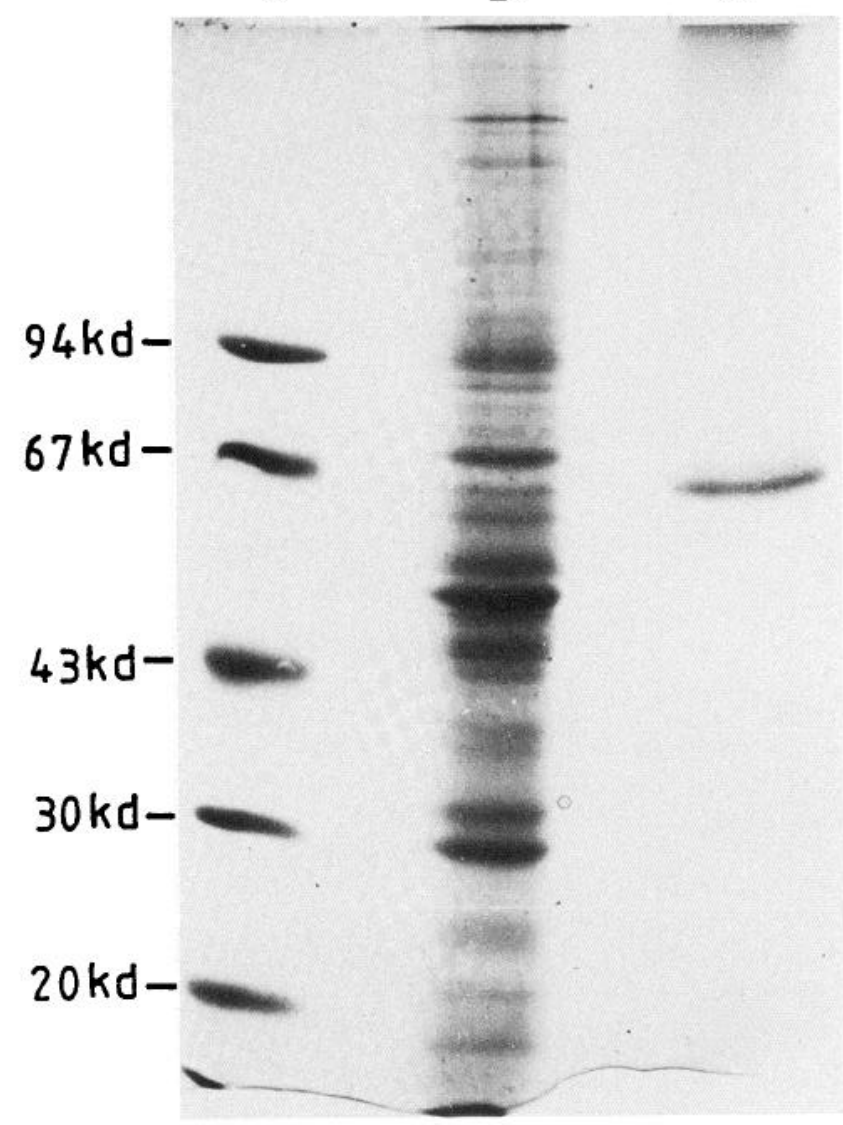

Figure 4. Analysis of the polypeptide composition of a deoxycholate extract from a neuronal membrane preparation (lane 2) and of proteins eluted from the affinity gel by carbamylcholine (lane 3 ) using a continuous polyacrylamide gel $(12.5 \%)$ under denaturing conditions. Lane 1 shows the standard proteins used (Pharmacia LMW calibration kit: phosphorylase $b=$ $94 \mathrm{kd}$, albumin $=67 \mathrm{kd}$, ovalbumin $=43 \mathrm{kd}$, carbonic anhydrase $=30 \mathrm{kd}$, trypsin inhibitor $=20.1 \mathrm{kd}$, lactal albumin $=14.4 \mathrm{kd}$ ). It is evident that only one band out of the diversity of polypeptides found in the membrane extract (lane 2) was adsorbed by the affinity gel and was eluted with cholinergic ligands; i.e., the affinity-purified receptor is obviously composed of identical or very similar polypeptides $\left(M_{\mathrm{r}}=65,000\right)$.

5 , in the presence of DTT the protein stain in the 130-kd position disappeared, whereas the peak at the 65-kd position increased simultaneously, indicating that the $130-\mathrm{kd}$ polypeptides were converted into $65-\mathrm{kd}$ units by the action of reducing agents. Similar results were obtained with 2-mercaptoethanol, suggesting that the $65-k d$ monomers are interlinked via disulfide bridges. However, the link seems not to be extremely strong since the monomeric form was also predominantly found after prolonged incubation at room temperature. The gel position of the subunit monomer could not be changed by prolonged detergent treatment or by using higher concentrations of detergents or reducing agents. Thus, the $65-\mathrm{kd}$ polypeptide seems to represent the constituent of the acetylcholine receptor in the CNS of the locust.

In a recent study we have demonstrated that a few antibodies from a library of monoclonal antibodies raised against the acetylcholine receptor from Torpedo marmorata (Watters and Maelicke, 1983) showed considerable cross-reactivity with neuronal membrane preparations from locust ganglia (Fels et al., 1983). In order to evaluate whether these antibodies recognize the isolated subunits of the locust receptor as well, polypeptides were separated by SDSpolyacrylamide gel electrophoresis and transferred in a renaturing environment on nitrocellulose sheets by electroblotting. Incubation 


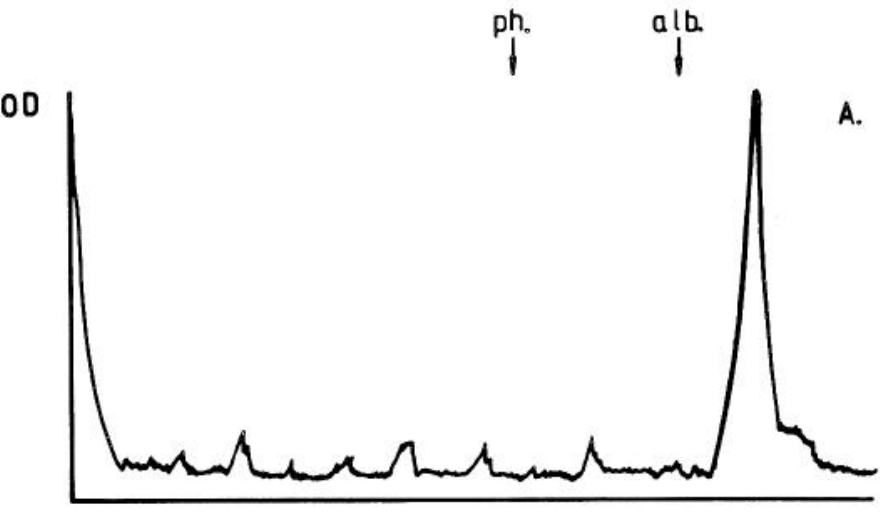

OD

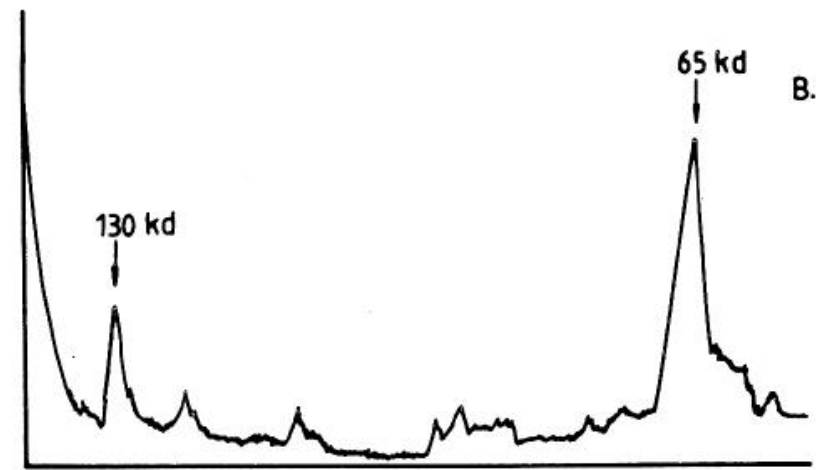

00

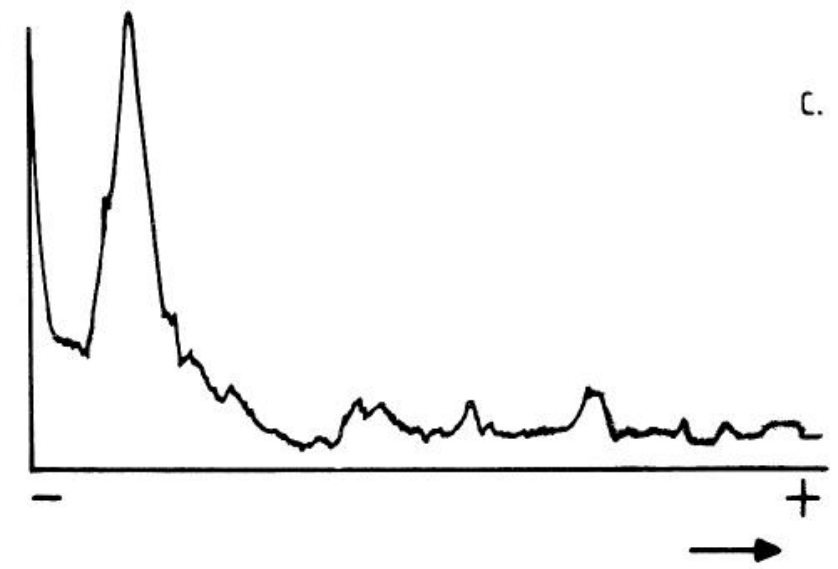

Figure 5. Densitometric scanning of a continuous $12.5 \%$ polyacrylamide gel after electrophoresis of purified receptor protein treated with $1 \%$ SDS sample buffer without DTT $(A)$, with $2 \%$ DTT $(B)$, or with $5 \%$ DTT $(C)$. Markers: ph., phosphorylase; alb., albumin.

with supernatant of the hybridoma clone N2-A9-E10 followed by a visualization procedure showed that the insect receptor subunits were recognized by this antibody (Fig. 6). The significant antigenic cross-reactivity between insect bungarotoxin-binding protein and the Torpedo acetylcholine receptor represents independent evidence that the isolated 65-kd polypeptide is a constituent of the acetylcholine receptor in locust and implies some structural homology both receptor types.

Further evidence for establishing the receptor nature of the identified polypeptides may be received by investigating its location in the nervous system of the locust, using an immunohistochemical approach. Antibodies against the affinity-purified polypeptides were raised in rabbits and applied to tissue sections of the locust thoracic ganglia followed by unlabeled goat anti-rabbit lgG and then the soluble complex of peroxidase-rabbit antiperoxidase. Using this procedure it could be demonstrated that the antigenic sites are distributed in very distinct areas of the neuropil, zones which are very rich in neuronal connections (Fig. 7). No labeling was detected over the ganglion-surrounding sheaths and the peripheral cell layers. Thus, the appearance of the antigenic sites in immunocytochemical preparations is consistent with its location at neuronal synapses.

\section{Discussion}

The purified acetylcholine receptor from the CNS of insects exists as a homogenous protein species, when isolated under conditions designed to minimize proteolytic degradation; it gives a single peak by centrifugation on sucrose gradients and it migrates as a single protein band by polyacrylamide gel electrophoresis under nondenaturing conditions. The identification of this protein as acetylcholine receptor is based on its saturable binding of $\alpha$-BGTX specifically inhibited by nicotinic cholinergic ligands (Breer et al., 1984) which resembles the pharmacology found for the ligands to block cholinergic transmission in the ganglia of insects (Sattelle et al., 1980). Furthermore, the solubilized (Fels et al., 1983) and purified receptor protein (Fig. 6) showed a significant immunological cross-reactivity to the identified acetylcholine receptor from Torpedo. Additional support for its identity comes from the specific location of the 65-kd antigenic polypeptide in very distinct areas of the neuropil from locust ganglia as revealed in immunohistochemical studies with rabbit anti-(65-kd protein) antiserum; the immunoreactive sites were found concentrated in zones of the neuropil which are supposed to contain cholinergic synapses. Furthermore, current approaches to reconstitute the affinity-purified receptor protein in planar lipid bilayers succeeded in demonstrating that the affinity-purified receptor protein

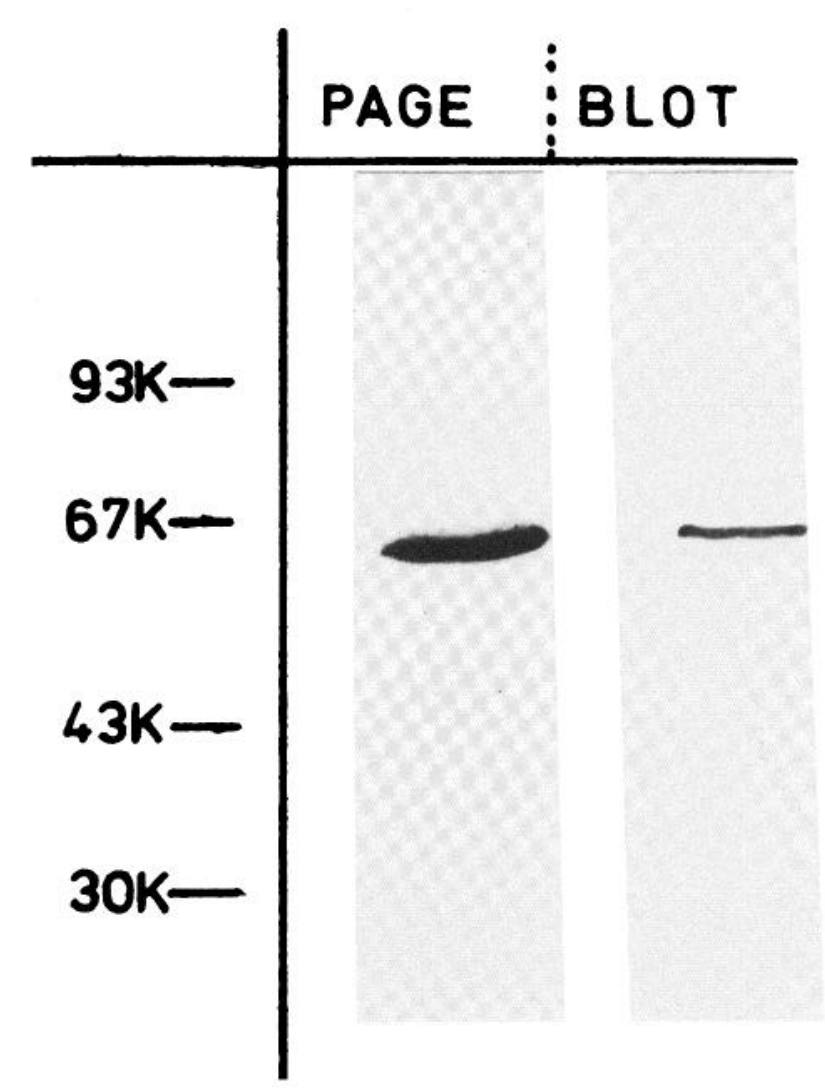

Figure 6. Immunoblot staining of Locusta acetylcholine receptor using a monoclonal antibody against Torpedo receptor. Affinity-purified receptor protein was separated by SDS electrophoresis and visualized with silver stain (left) or transferred to nitrocellulose sheets, which were incubated with hybridoma supernatant. Cross-reacting antibodies were visualized with peroxidase-conjugated anti-mouse lgG and peroxidase (right). 


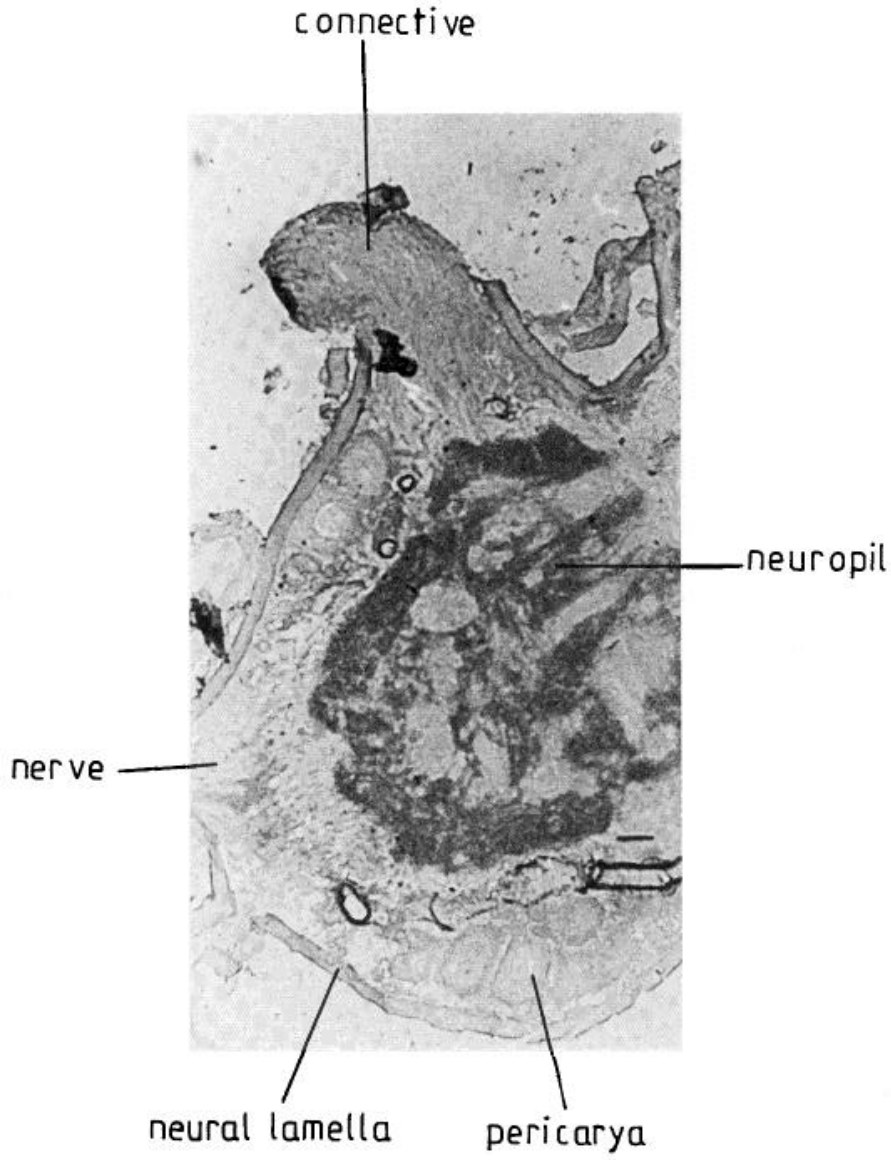

Figure 7. Localization of antigenic sites in locust mesothoracic ganglia. Cross-sections $(20 \mu \mathrm{m})$ were treated with antisera followed by goat antirabbit IgG and peroxidase-antiperoxidase. Note the heavy labeling of distinct areas in the neuropil.

is indeed able to transduce acetylcholine agonist binding into a cation-specific permeability increase (W. Hanke and $\mathrm{H}$. Breer, manuscript in preparation). Thus, it seems reasonable to conclude that the purified protein is in fact the acetylcholine receptor itself or an integral part of what could be a larger functional receptor unit in the membrane.

The size of the receptor protein appears to represent an apparent $M_{\mathrm{r}}=250,000$ to 300,000 as determined by gradient gel electrophoresis, cross-linking experiments, and the sedimentation coefficient. The apparent higher molecular weight determined by gel filtration is obviously overestimated due to detergent binding, as was observed for other membrane proteins (Biesecker, 1973).

Treatment of the macromolecular receptor protein with denaturing conditions (SDS, DTT) caused its dissociation into subunits of apparently identical size $\left(M_{\mathrm{r}}=65,000\right)$. If there is any microheterogeneity of the subunits, it will be revealed by forthcoming analytical studies using two-dimensional electrophoresis. Whether the subunits are assembled via S-S bridges in the native receptor complex as may be supposed by the results of nonreducing electrophoresis has to be substantiated. Nevertheless it appears from the present study that the native acetylcholine receptor in the central nervous tissue from insects is a membrane protein with a molecular size of 250,000 to 300,000 , which represents an oligomeric complex of four identical or very similar polypeptides $\left(M_{\mathrm{r}}=65,000\right)$.

The suggestion that the acetylcholine receptor from insects represents a tetramer of 65-kd subunits holds a certain measure of appeal since it has been noted that complex proteins are generally constructed from identical or very related subunits (Matthews and Bernhard, 1973).
The homo-oligomeric organization of the insect receptor is furthermore of particular interest in view of the evolution of the nicotinic acetylcholine receptor. Based on immunological studies and the amino acid sequence homology of the four different polypeptides forming the acetylcholine receptor in vertebrate peripheral synapses, a common genetic origin during evolution of the receptor constitutents has been suggested; the genes coding for the subunits of the receptor protein must have originated from a common ancestral gene via duplication (Raftery et al., 1980; Noda et al., 1983). The likely existence of such a unique acetylcholine-binding ancestral protein is supposed to have been a homo-oligomeric complex from which the recent hetero-oligomeric receptors have evoled (Popot and Changeux, 1984).

Whether the identified homo-oligomeric acetylcholine receptor from the insect species, Locusta migratoria, which is classified in the phylogenetically rather ancient insect order, Orthoptera, and which is thus far apart from vertebrates on the evolutionary scale, can be considered as a representative of an ancient form of acetylcholine receptoris unclear yet. However, the determination of the amino acid sequence at the $\mathrm{N}$-terminal of the insect receptor protein and in particular the elucidation of its complete primary structure by cloning and sequencing cDNAs for this polypeptide will show whether there are any significant structural similarities between the insect and the Torpedo receptor and may shed some new light on the molecular evolution of the acetylcholine receptor. In a first approach the nervous tissue of locust was probed for receptorspecific mRNA using Xenopus oocytes as an assay system for identifying the mRNA coding for $\alpha$-BGTX-binding protein (Breer and Benke, 1985).

Another aspect of interest points to the possibility that a homooligomeric organization may be an attribute of acetylcholine receptors from nerve cells in general. Whereas a hetero-oligomeric structure has been demonstrated only for receptors in electroplaques or muscle cells, there are some reports indicating that the $\alpha$-BGTXbinding protein of chick optic lobe (Betz et al., 1982; Norman et al., 1982) and mouse brain (Seto et al., 1981) and the binding sites for nicotine in rat brain (Abood et al., 1983) may represent complexes of subunits with $M_{r}=51,000$ to 57,000 . Immunochemical studies using monoclonal antibodies against the chick optic lobe binding sites (Betz and Pfeifer, 1984) may contribute to elucidating any molecular relationship between binding sites from insect and chick nervous tissue.

\section{References}

Abood, L. G., W. Latham, and S. Grassi (1983) Isolation of a nicotinic binding site from rat brain by affinity chromatography. Proc. Natl. Acad. Sci. U. S. A. $80: 3536-3539$.

Ashami, Y., and G. N. Catravas (1980) Highly reactive impurities in Triton X100 and Brij 35: Partial characterization and removal. Anal. Biochem. 109: $146-152$.

Betz, H., and F. Pfeiffer (1984) Monoclonal antibodies against the $\alpha$-bungarotoxin-binding protein of chick optic lobe. J. Neurosci. 4: 2095-2105.

Betz, H., D. Graham, and H. Rehm (1982) Identification of polypeptides associated with a putative neuronal nicotinic acetylcholine receptor J. Biol. Chem. 257: 11390-11394

Biesecker, G. (1973) Molecular properties of the cholinergic receptor purified from Electrophorus electricus. Biochemistry 12: 4403-4409.

Breer, H. (1981a) Comparative studies on cholinergic activities in the central nervous system of Locusta migratoria. J. Comp. Physiol. 141: 271-275.

Breer, H. (1981b) Properties of putative nicotinic and muscarinic cholinergic receptors in the central nervous system of Locusta migratoria. Neurochem. Int. 3: 43-52.

Breer, H., and D. Benke (1985) Synthesis of acetylcholine receptors in Xenopus oocytes induced by poly $(\mathrm{A})^{+}$-mRNA from locust nervous tissue. Naturwiss. 72: 213-214

Breer, H., R. Kleene, and D. Benke (1984) Isolation of a putative nicotinic acetylcholine receptor from the central nervous system of Locusta migratoria. Neurosci. Lett. 46: 323-328. 
Burnette, W N (1981) "Western Blotting": Electrophoretic transfer of proteins from sodium dodecyl sulfate-polyacrylamide gels to unmodified nitrocellulose and radiographic detection with antibody and radioiodinated protein A. Anat. Biochem. 112: 195-203

Conti-Tronconi, B. M., and M. Raftery (1982) The nicotinic cholinergic receptor: Correlation of molecular structure with functional properties. Annu. Rev. Biochem. 51: 191-530.

Dudai, Y. (1979) Cholinergic receptors in insects. Trends Biochem. Sci. 4: 40-44

Eschenbruch, M., and R. R. Bürk (1982) Experimentally improved reliability of ultrasensitive silver staining of protein in polyacrylamide gels. Anal. Biochem. 125: 96-99.

Fels, G., H. Breer, and A. Maelicke (1983) Are there nicotinic acetylcholine receptors in invertebrate ganglionic tissue? In Toxins as Tools in Neurochemistry, F. Hucho and Y. A. Ovchinnikov, eds., pp. 127-140, de Gruyter, Berlin.

Florey, E. (1963) Acetylcholine in invertebrate nervous system. Can. J. Biochem. Physiol. 41: 2619-2626.

Laemmli, U. K. (1970) Cleavage of structural proteins during the assembly of the head of bacteriophage T4. Nature (Lond.) 227: 680-685

Lindström, J., B. Einarson, and S. Tzartos (1981) Production and assay of antibodies to acetylcholine receptors. Methods Enzymol. 74: 432-460.

Maelicke, A. (1984) Biochemische Aspekte der cholinergen Reizung. Angew. Chem. 96: 193-219

Matthews, B. W., and S. A. Bernhard (1973) Structure and symmetry of oligomeric enzymes. Annu. Rev. Biophys. Bioeng. 4: 257-317

McGeer, P. L., J. C. Eccles, and E. G. McGeer (1978) Molecular Neurobiology of the Mammalian Brain, pp. 149-181, Plenum Press, New York

Meunier, J. -C., R. Sealock, R. Olsen, and J. -P. Changuex (1974) Purification and properties of the receptor protein from Electrophorus electricus electric tissue. Eur. J. Biochem. 45: 371-394.

Morley, B. J., and G. E. Kemp (1981) Characterization of a putative nicotinic acetylcholine receptor in mammalian brain. Brain Res. Rev. 3: 81-104.

Noda, M., H. Takahashi, T. Tanabe, M. Toyoato, S. Kikyotani, Y. Furutani, T. Hirose, H. Takashima, S. Inayama, T. Miyata, and S. Numa (1983) Structural homology of Torpedo californica acetylcholine receptor subunits. Nature 302: 528-532

Norman, R. I., F. Mehraban, E. A. Barnard, and J. O. Dolly (1982) Nicotinic acetylcholine receptor from chick optic lobe. Proc. Natl. Acad. Sci. U. S. A. 79: 1321-1325

Oswald. R., and J. A. Freeman (1981) Alpha-bungarotoxin binding and central nervous system nicotinic acetylcholine receptors. Neuroscience 6 : $1-14$.

Poehling, H. M., and V. Neuhoff (1980) One- and two-dimensional electrophoresis in microslab gels. Electrophoresis 1: 1454-1465.

Popot, J. -L., and J. .P. Changuex (1984) Nicotinic receptor of acetylcholine: Structure of an oligomeric integral membrane protein. Physiol. Rev. 64 : 1162-1239.

Raftery, M. A., M. W. Hunkapiller, C. D. Strader, and L. E. Hood (1980) Acetylcholine receptor: Complex of homologous subunits. Science 208: 1454-1457.

Rüchel, R., D. Watters, and A. Maelicke (1981) Molecular forms and hydrodynamic properties of acetylcholine receptor from electric tissue. Eur. J. Biochem. 119: 215-223.

Salvaterra, P. M., and R. M. Foders (1979) ${ }^{125} \alpha$-bungarotoxin and ${ }^{3} H$ quinuclidinylbenzilate binding in the central nervous system of different species. J. Neurochem. 32: 1509-1517.

Salvaterra, P. M., G. D. Crawford, J. C. Klotz, and U. Ikdea (1985) Production and use of monoclonal antibodies to biochemically defined insect neuronal antigens. In Neurochemical Techniques in Insect Research, $\mathrm{H}$. Breer and T. A. Miller, eds., pp 223-238, Springer-Verlag, Heidelberg.

Sattelle, D. B., J. A. David, I. D. Harrow, and B. Hue (1980) Actions of $\alpha$ bungarotoxin on identified insect central neurons. In Receptors for $\mathrm{Neu}$ rotransmitters, Hormones and Pheromones in Insects, D. B. Sattelle, L. Hall, and J. G. Hildebrand, eds., pp. 125-139, Elsevier-North Holland Publishing Co., Amsterdam.

Seto, A., Y. Arimatsu, and T. Amano (1981) Subunit structure of $\alpha$-bungarotoxin binding component in mouse brain. J. Neurochem. 37: 210-216.

Schmidt, J., and M. A. Raftery (1973) A simple assay for the study of solubilized acetylcholine receptors. Anal. Biochem. 52: 349-354.

Towbin, H., T. Staehelin, and J. Gordon (1979) Electrophoretic transfer of proteins from polyacrylamide gels to nitrocellulose sheets: Procedure and some applications. Biochemistry $76: 4350-4354$

Watters, D., and A. Maelicke (1983) Organization of ligand binding sites at the acetylcholine receptor. A study with monoclonal antibodies. Biochemistry 22: 18111819 